\title{
OBSERVATION OF DYNAMIC PROCESSES IN CUTTING ZONE WHEN MACHINING NICKEL ALLOYS
}

\begin{abstract}
Process models of super alloys and included finite element modelling simulations are important for optimizing the metal cutting process, allowing industry to make parts faster, better, and at less cost. Innovative measurement methods of the process can be used to improve and verify the accuracy of these models. With these methods, there are many sources of error when using empirical or exact methods such as infrared radiation thermography to measure the temperature distribution of the tool, workpiece, and chip during metal cutting. Furthermore, metal cutting presents unique measurement challenges due to factors such as the high magnification required, high surface speeds and deformations, micro-blackbody effects, changing emissivity, and primary, secondary and tertiary deformations. As part of an ongoing effort to improve our understanding of the uncertainties associated with these measurement methods, multi-measurement sets of experiments were performed. One set explored how accurately the surface temperature of the cutting tool reflects the internal temperature. This was accomplished by measuring the temperature using a thermal camera in the cutting zone. The second set provided high-speed scanning of dynamic processes such as formation of elastic and plastic deformation. For this measurement, a high-speed scanning system was applied, with a macro conversion lens for monitoring micro-structural changes in deformation areas. The next set applied was necessary for recording dynamic processes by the implementation of a piezoelectric measurement device for monitoring cutting forces. The outputs from this multi-measuring system are the basis for verification of theoretical knowledge from this field and elimination of the uncertainties that arise with computational simulation systems.

Keywords: Nickel alloys, cutting zone, multifunction measuring system, high-speed imaging, infrared thermography.
\end{abstract}

\section{Introduction}

Cutting process analytical modelling allows us to understand the basic principles of the metal cutting phenomena while reducing the dependence on empiricisms by avoiding a large amount of time-consuming experiments. What is more important, it enables the evaluation of the main process factors such as force of cutting and aids in its prediction, which is required for the optimal execution of the machining operation. Many analytical models have been developed to date which can determine the relations between the variables involved in the cutting process. It is generally accepted that the cutting process in the course of metal machining is restricted to the area in front of the tool cutting edge due to intensive local shear deformation of the machined material [1 and 2].

Most of the current analytical models describe the cutting process as a simple two-dimensional model named orthogonal cutting. However, most cutting operations are actually threedimensional and can be properly described using an oblique cutting model where the cutting edge is inclined at an angle of obliquity, $\lambda$, consistent with the primary motion course of the workpiece. Nevertheless, the simplified orthogonal model is generally used as a good demonstration of the oblique model. Figure 1 illustrates the orthogonal and oblique cutting models. In Fig. 1c, the workpiece, initially moving at speed $v$, goes through a plastic shearing strain and that leads to a chip streaming at speed $v_{c}$ after passing a certain shear area exemplified by the shear plane $\mathrm{AB}$. Due to its importance as a measure of the energy efficiency of the cutting process, the shear plane orientation, $\phi$, is essential to analytical models for the development of the cutting process [ 3 and 4 ]. In addition to the stress at the cutting area, the orientation of the shear plane affects the kinematics of the machining process too. Merchant [5] designed the most simple and widely used model to determine the shear plane angle. $\mathrm{He}$ constituted a mathematical concept for describing force relationships in the cutting process.

\footnotetext{
* Andrej Czan, Michal Sajgalik, Anton Martikan, Jozef Mrazik

Department of Machining and Manufacturing Technology, Faculty of Mechanical Engineering, University of Zilina, Slovakia

E-mail: andrej.czan@fstroj.uniza.sk
} 


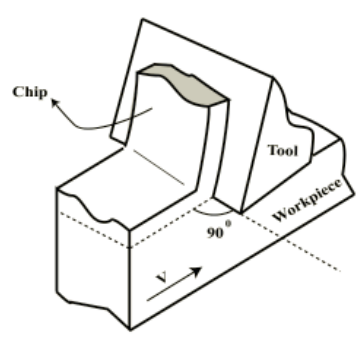

(a)

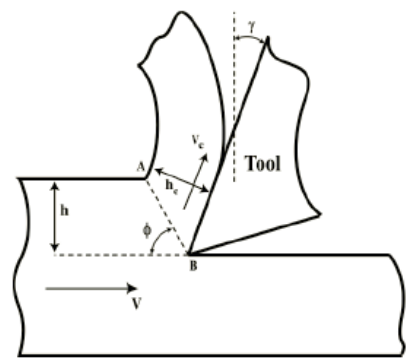

(c)

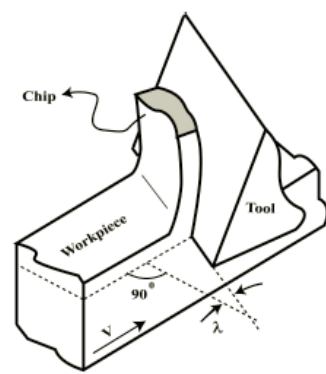

(b)

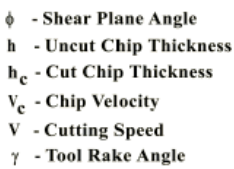

$\gamma$ - Tool Rake Angle

Fig. 1 a) Orthogonal cutting model; b) Oblique cutting model; c) General 2D representation of the cutting process with the variables of the cutting process [6]

Another premise of Merchant's force of cutting model is that the whole shearing action is restricted to a single plane of deformation. Lee and Shaffer [7] chose another approach and modelled the cutting process based on the plasticity theory. Lee and Shaffer's model expects that plastic deformation spreads over the defined shear zone represented by $\triangle \mathrm{ABC}$. There is uniform stress presumed within the shear zone without work hardening effects. The complete shearing action is expected to occur along parallel lines of slip within the shear zone. Lee and Shaffer's model also presumes that the maximum shear stress is orientated in the same direction as the shear plane AC.

Zorev [8] pointed out incongruities of both the single shear plane and homogeneous stress slip-line theoretical models. He concluded that both models are limited in their premises; the slipline model does not consider the real aspect of work hardening (and thus no stress gradient) during machining, while the single shear plane model ignores the enormous velocity deceleration of the work material from speed $\mathrm{v}$ to speed $v$. Zorev designed a shear plane model shown in Fig. 2 a) which describes the shear zone by a series of distinct shear planes, each defined by continuously varying shear stress values and velocity gradients. A simplified version of this model is shown in Fig. 2 b) and presents the shear zone as series of straight shear planes each with a different shear angle.

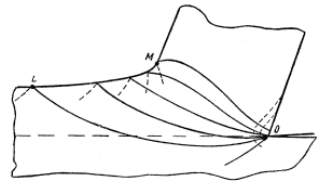

(a)

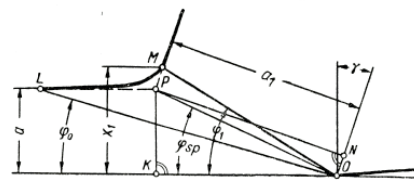

(b)
Fig. 2 a) Zorev's curved slip line model, b) The simplified version of the curved slip line model (Zorev, 1966)

Palmer and Oxley [9] experimentally studied the cutting process using a cinematography technique. Their results validated the multi-shear plane theory. They also concluded that tool-chip contact occurs some distance away from the tool tip, resulting in a kinematic dead zone at the tool tip. It was incorrectly assumed that no further plastic deformation occurs as the chip contacts the tool face and the secondary deformation observed is larger due to elastic chip flattening at this point. As proven conclusively from the later experimental work of Wallace and Boothroyd [6], the chip continues to undergo plastic deformation via shear upon contact with the tool rake face. A similar theory was included in Zorev's [8] work on predicting the shear zone area.

Thus, two major deformation zones called the Primary Deformation Zone (PDZ) and Secondary Deformation Zone (SDZ) can be identified in the metal cutting process. The second occurs because of shear due to the contact friction conditions between the chip and the tool rake face. Based on experimental observations, Roth and Oxley [10] developed a slip-line field model using velocity-dependent material flow lines that definitively identify the PDZ and SDZ. Based on the latter set of slip-line field models, the orthogonal cutting process can be presented as shown in Fig. 3. Depending on the subject matter under consideration, both single shear plane models and slip-line models have been used alternatively by researchers to study the cutting process [11]. Aside from the seminal work already mentioned, several excellent analytical models characterizing cutting mechanics are available. A list of analytical models is presented by Shaw [3] and will not be mentioned here for brevity.

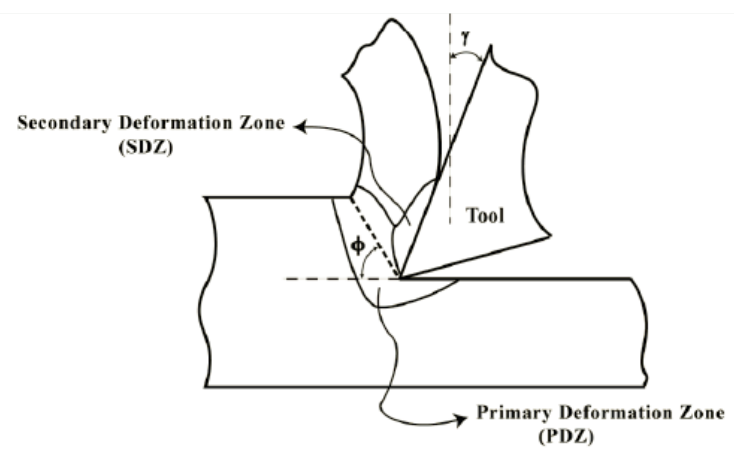

Fig. 3 Orthogonal schema showing primary and secondary deformation zones 


\section{Multifunction measuring system}

The modelling system FEM is an important tool for rationalization of the metal cutting process, allowing industry to make parts faster, better, and at less cost but mainly ensuring the functional characteristics [12 and 13]. Innovative measurement methods of the process using thermal systems, high-speed scanning of dynamic processes and influence can be used to improve and verify the accuracy of these models. Four goals of manufacturing-related research at the Department of Machining and Manufacturing are: to develop and improve measurement techniques, to develop an understanding of the uncertainties involved with performing such measurements, to compare models of machining with thermal and visible spectrum images to verify the models, and to share this understanding with the machining community [14 and 15]

The formation of individual deformation zones is shown in Fig. 4, which shows a schematic of a typical image of an orthogonal cutting process. The relative motion between a cutting tool and a workpiece causes material to be removed from the workpiece. This removed material is referred to as a formation chip. Most of the deformation of the workpiece material occurs within a thin area called the shear zone [16 and 17].

Two of the many types of chips are called continuous and segmented. A continuous chip is a long ribbon of relatively uniformly deformed material. By contrast, a segmented chip has alternating zones of low and high shear strain. A zone of low strain in a segmented chip is called a segment. The zones of high strain between the segments are mechanically weak, so the long ribbons of material tend to break into short pieces [18]. These short pieces are more manageable than a continuous chip. Even when segmented chips do not break completely, there is generally a partial gap between the segments. The shear zone is somewhat stationary when continuous chips are formed, but often travels along with the chips when the chips are segmented. We will call the area surrounding the shear zone the face of the chip. The shear zone has a higher temperature than the face. For segmented chips, the shear zone generally also has a higher emissivity than the face [19 and 20].

The system used for measuring and observation processes in the cutting zone consists of a high-speed imaging camcorder, thermo-vision system and dynamometer for measurement of the cutting forces. Besides these sub-devices, there is a laboratory cold light for lighting the studied area and a computer for synchronizing all the measured data. This multi-axis measuring system (Fig. 4) was designed for the universal lathe SUI-40, but the construction of the stand guarantees some universality of the measuring system for other types of machines.

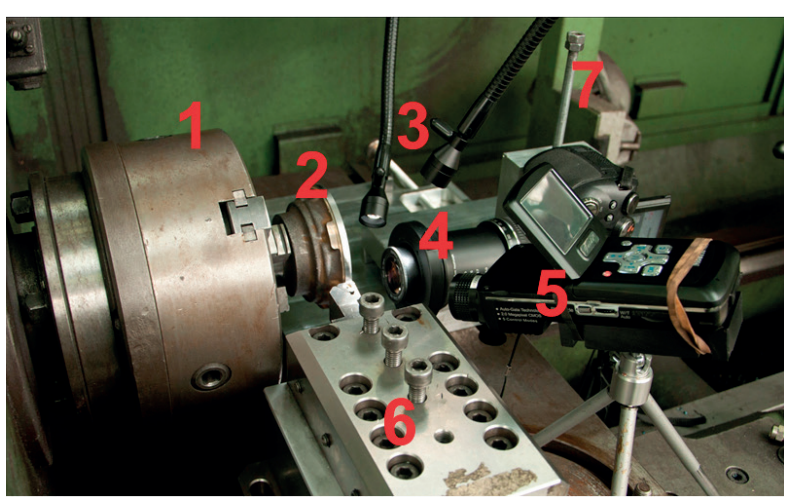

Fig. 4 Multifunction measuring system, 1 - chuck; 2 - sample; 3 - cold light; 4 - high-speed imaging camcorder, 5 - thermo-vision system; 6 - dynamometer with tool; 7 - macro-stand

Dynamical monitoring of the cutting process can be provided by the high-speed imaging camcorder, which ensures high-speed imaging in all experiments, with an imaging frequency of $1000 \mathrm{fps}$. For detailed study, a super-macro lens Raynox MSN-202 with 20x magnification was used. Based on this optical system, we can capture an area of $4 \mathrm{~mm} \times 3 \mathrm{~mm}$.

The actual heat distribution can be monitored by the thermovision system which captures the thermal field in the cutting zone and heat distribution when machining. This compact camera allows us to measure temperatures up to $1200^{\circ} \mathrm{C}$ with a tolerance of $\pm 2^{\circ} \mathrm{C}$. Special optics with deflected lens allows us to place the camera outside of the perpendicular on the scanned object [14].

The piezoelectric 3-component dynamometer can capture fast dynamic force relations measured as cutting forces with highspeed scanning up to $1 \times 10^{5} \mathrm{~Hz}$. All the applied measuring devices are integrated on a macro-stand (Fig. 5). For correct mounting and manipulation, the macro-stand was designed with mounting on the lathe support in order to ensure the simultaneous motion of the camera and cutting tool.

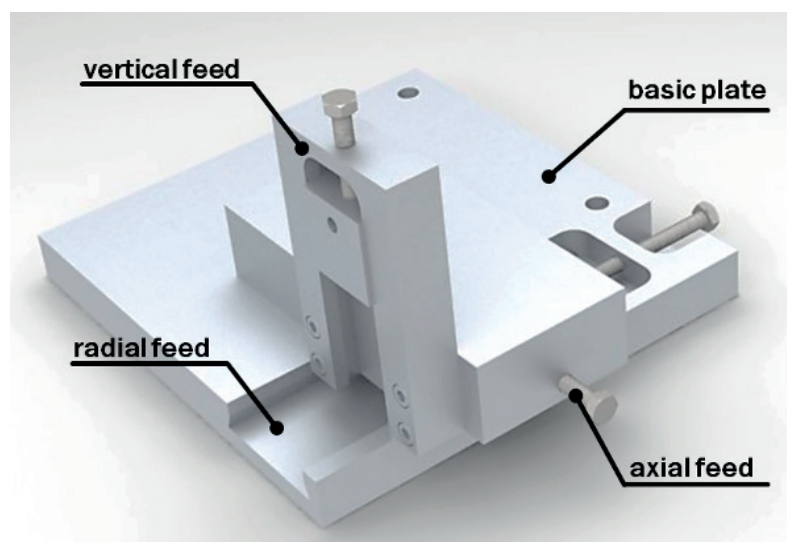

Fig. 5 Macro-stand with triaxial feed for mounting of high-speed imaging camcorder which provides simultaneous movement of the cutting tool and camcorder 
Nickel alloys are popular materials due to their high heat and creep resistance. Due to their specific properties, they are used in the aerospace industry. Due to their mechanical and chemical properties, they are included among the hard-machined materials. Because this material is characterized as having a combination of strength, toughness and hardness, it is necessary to choose specific cutting conditions [21 and 22]. These were chosen from the real cutting conditions used in practice and they are shown in the caption of Fig. 6. All experiments were performed without coolant because this would prevent the scanning by the highspeed thermo-graphic camera [23 and 24].

To prevent the influence of bound-cutting by the cutting edge effect, the technology of free-cut turning was chosen. The free cutting approach ensures as much as possible of the area of the cutting zone and also ensures that the chips depart in the opposite direction of action from that of the cutting tool [25 and 26].

\section{Evaluation of the experiments}

Measurements of cutting forces were conducted in various cutting conditions. As we can see, the cutting force Ff increased with the increasing feed and, conversely, cutting force $\mathrm{Fc}$ decreased with increasing cutting speed (Fig. 6). It can be deduced from the measured data that the behaviour of nickel alloy Monel 400 is similar to the machining austenite of steel, but with a higher ratio of cutting forces considering the mechanical properties of this alloy.

From the monitoring of the dynamic course of the cutting forces, we can say that the cutting process is created by frequent accumulation of material as the built-up edge. The built-up edge has considerable influence on the cutting geometry, which causes the high dynamization of the cutting process.

Methods of examining and monitoring the cutting zone are developing with available technologies that are applicable for the monitoring and capturing of processes during the cutting
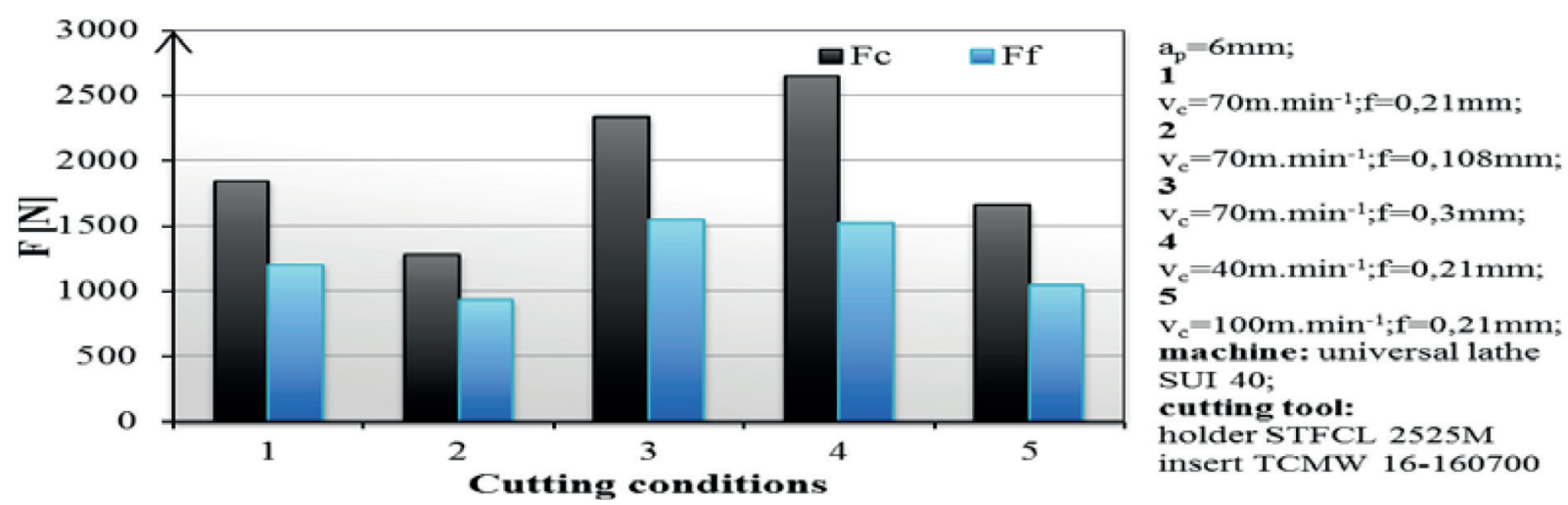

Fig. 6 Static values of cutting forces in various cutting conditions
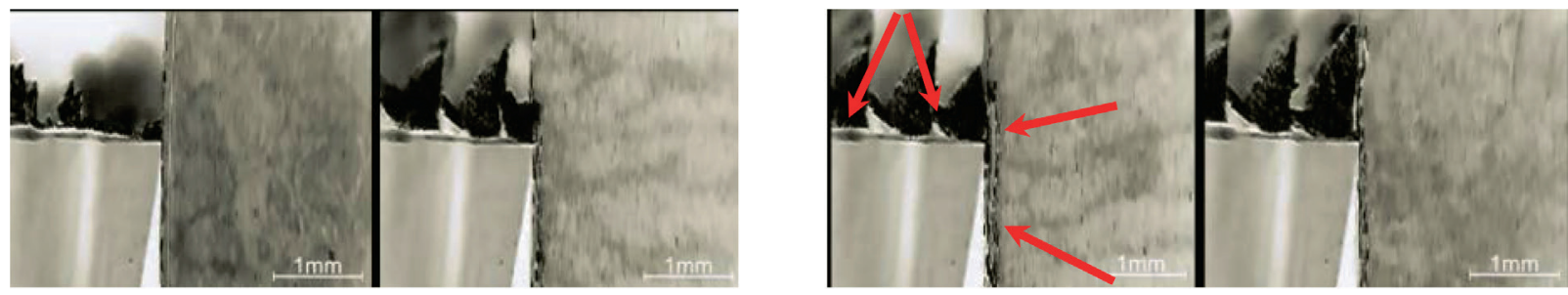

Fig. 7 Cutting process with continuous cut and minimal cutting speed $v_{c}=40 \mathrm{~m} . \mathrm{min}^{-1}$ and feed $0.21 \mathrm{~mm}$, rise of elementary chip and deformation areas of plastic and elastic deformation
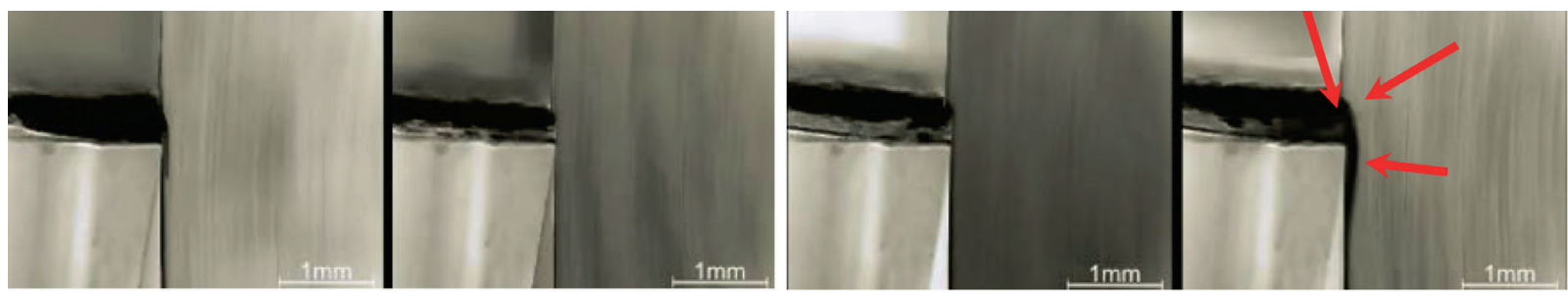

Fig. 8 Cutting process with continuous cut and maximal cutting speed $v_{c}=100$ m.min ${ }^{-1}$ and feed $0.21 \mathrm{~mm}$, formation of continuous ribbon chip and deformation areas of plastic and elastic deformation 

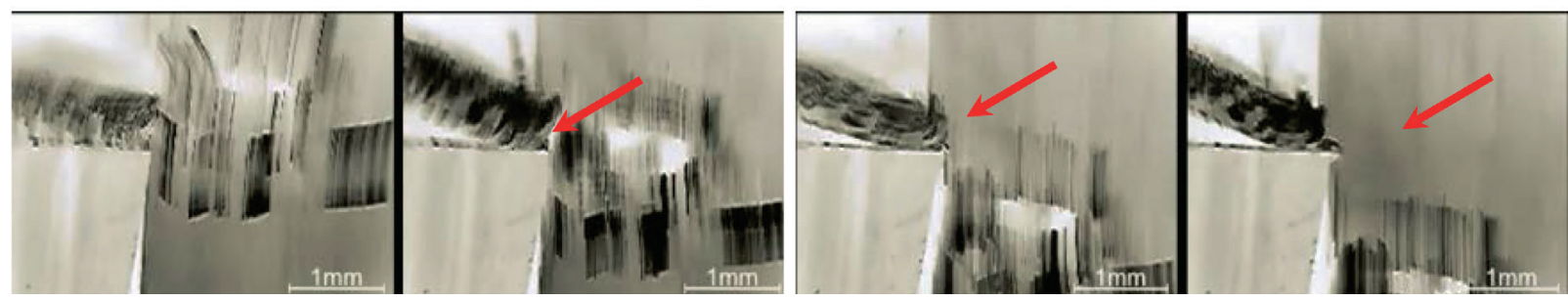

Fig. 9 Cutting process with continuous cut and maximal cutting speed $v c=100 \mathrm{~m} . \mathrm{min}-1$ and feed $0.21 \mathrm{~mm}$, formation of continuous ribbon chip and deformation areas of plastic and elastic deformation

process [27]. The most common possibilities include research of deformation processes based on finished changes after the end of the cutting process, such as examining metallographic samples from the cutting zone, acquired by the immediate interruption of the cutting process, etc. [28 and 29]. This research reached sufficient and complete conclusions about the processes in the cutting zone, but in a static concept after the finished process. Therefore, it was necessary to find new innovative technologies for idealized physico-mathematical models as the previous experimental outcomes provide information about finished processes only [30 and 31]. It is necessary to record deformation processes in the form of a high-speed video and image sequences from which the creation, shape of chips and deformations in the cutting zone when machining can be evaluated, and these can be made from monitoring the cutting zone by a high-speed imaging camcorder [32 and 33].

In the high-speed video records, it is possible to see the formation of deformation processes depending on the cutting conditions. At low cutting speeds, the formation of elementary chips occurs, giving rise to high dynamic shocks which load and cyclically fatigue the cutting edge up to destruction (Fig. 7).

At the higher cutting speeds, the formation of continuous ribbon chip occurs, which has a different character of influence on the cutting edge where thermal effects outweigh the dynamic shocks and cyclic loadings (Fig. 8).

In the last picture (of Fig. 8) of the measuring system, the primary and tertiary area and their influence on the machined surface can be seen. This surface has the effect of pooling the high stress loadings which act negatively on the functional properties of parts.

By application of the notch, there was simulation of discontinuous cut in which the monitoring of the cutting process before and after tensioning of the technological system was important. Cutting conditions were identical to the conditions of the continuous cut. In this experiment, there is formation of the same chip which has an identical character to that in the previous experiment. The cutting edge of the cutting tool is exposed to temperature mainly and dynamic shock and cyclic loadings (Fig. 9).

In each picture of the measuring system, relaxation of the technological system (tool - workpiece) can be seen with the transition to the tensioning of the technological system. These images show the formation of deformation processes, and are thus a suitable basis for new simulation and mathematical models.

The data obtained from the individual processes during the experiments have a direct relationship with each other because they were obtained simultaneously in a single machining process. In this case they provide especially a waveform record of the cutting forces, the time course of development of the temperature field, and visual records of the deformation phenomena during the machining process. The measured data were then processed on a computer into video clips that show how individual phenomena are associated with each other in the cutting zone (Fig. 10).

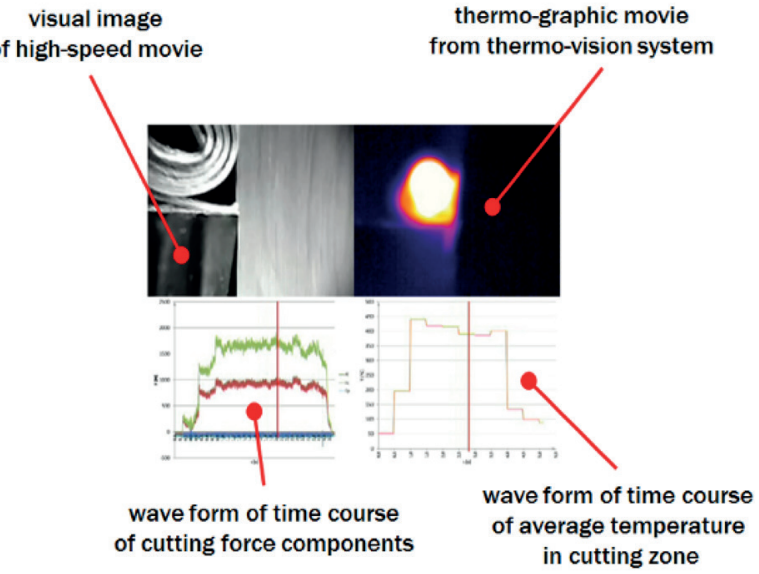

Fig. 10 Deployment of monitored processes in the video output of multifunctional measuring system [11]

Sequential frames from multi-parametric output are shown schematically: In the upper left corner is a visual record from the high-speed camera. In the top right corner is a thermo-graph or the thermo-graphic time course of the thermo-vision system (this is slowed down for the high-speed camera frame rate). Below the video output is the waveform of the components of the cutting force on the left and the graphic time course of the development of the average temperature in the cutting zone.

During the turning of the nickel alloy Monel 400, the phenomenon occurs that the primary contact of the tool and machined material is highly loaded with the pressure of transition from forming to the cutting process. In the first frame (Fig. 11 ), it is possible to see the formation of elementary chips after 

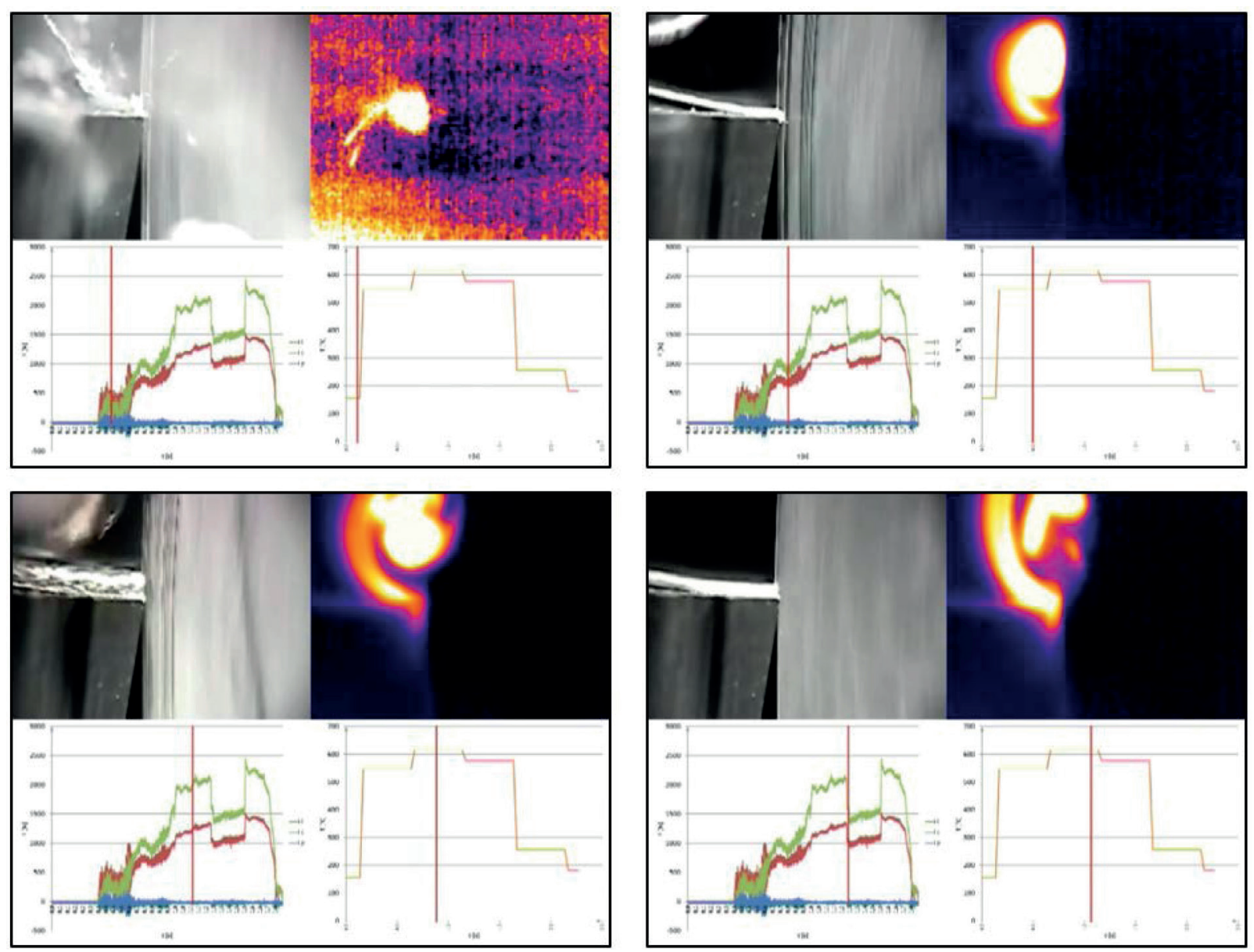

cutting conditions: continuous cutting; $v_{c}=70 \mathrm{~m} . \mathrm{min}-1 ; f=0,21 \mathrm{~mm} ; a_{p}=6 \mathrm{~m}$; machine: univ. lathe SUI-40; cutting tool: holder STFCL 2525M, insert TCMW 16-160700

Fig. 11 Selected frames from video output of the multifunction measuring system

the intrusion of the cutting tool into the action, and after the stabilization of the cutting process, flat spiral chips were created.

The microstructure and mechanical properties of the materials caused a built-up edge to form almost throughout the cutting process. The components of cutting force during the formation of the built-up edge and its subsequent "holding on" to the front face of the cutting tool grew very high. After being picked, the cutting forces decreased sharply. With the new creation of a built-up edge, the whole process was repeated. This iterative cycle resulted in a specific shape of waveform of the components of the cutting force. In the third frame of Fig. 11 the built-up edge and increased components of the cutting force can be seen. The last frame of Fig. 11 captures the moment immediately after the built-up edge is picked.

\section{Conclusions}

The multifunction measuring system designed for the monitoring of processes in the cutting zone allows observation of the deformations, temperature field, forming and shape of chip directly in the course of the cutting process, without interruption. We can evaluate the measured data in the specific dependences which exist between them.

The forces which act in the process change depending on the cutting conditions, structure and mechanical properties of the machined material.

The deformation processes which are in the cutting zone during machining take place at high speed. Under normal observation with the naked eye or by microscope only, these processes are not identifiable. Detailed observation is possible using the high-speed imaging camcorder. In this way, we can 
observe not only the deformation processes but also the creation and formation of chips.

With the multifunction measuring system, we can better intensify the machining process, cutting conditions and so improve the product quality. We can also reduce the cost, because this system allows simultaneous measuring. Based on the observations of the deformation processes in the cutting zone, as well as the creation and formation of chips, we can also optimize the shape of the cutting inserts.

\section{Acknowledgements}

This article was funded by the University of Zilina project OPVaV-2009/2.2/04-SORO number (26220220101) - "Intelligent system for nondestructive technologies on evaluation for the functional properties of components of X-ray diffraction “.

\section{References}

[1] CEP, R., OCENASOVA, L., NOVAKOVA, J., PETRKOVSKA, L., CZAN, A., STANCEKOVA, D.: Interrupted Machining Tests of Ceramic Cutting Tools, Proc. of TMT 2009, October 2009, Hammamet, vol. 13, No. 1, 733-736, ISSN 1840-4944.

[2] NOVAKOVA, J., PETRKOVSKA, L., BRYCHTA, J., STANCEKOVA, D.: Influence of Cutting Parameters on Integrity Surface at High Speed Cutting. Transactions of the VSB - Technical University of Ostrava, Mechanical Series, vol. LV., No. 1, 2009, $203-209$.

[3] SHAW, M. C.: Metal Cutting Principles, $2^{\text {nd }}$ Edition, 2005, Oxford University Press.

[4] LUKOVICS, I., BILEK, O., HOLEMY, S.: Application of Sintered Corundum by Manufacturing of Tools (in Czech), Strojirenska technologie, vol. XV, No. 3, 2010, 27-34, ISSN 1211-4162.

[5] MERCHANT, M. E.: Basic Mechanics of the Metal Cutting Process, J. of Applied Mechanics, V11, 168-175, 1944.

[6] BOOTHROYD, G., KNIGHT, W. A.: Fundamentals of Machining and Machine Tools, $3^{\text {rd }}$ ed., CRC Press, 2006.

[7] LEE, E. H., SHAFFER, B. W.: Theory of Plasticity Applied to a Problem of Machining, J. of Applied Mechanics, V18, 1951, 405413.

[8] ZOREV, N.N.: Metal Cutting Mechanics, Pergamon Press, 1966.

[9] PALMER, W. B., OXLEY, P. L. B.: Mechanics of Orthogonal Machining, Proc. of the Institution of Mechanical Engineers, V173, No. 24, 623-654, 1959.

[10] ROTH, R. N. AND OXLEY, P. L. B.: A Slip Line Field Analysis for Orthogonal Machining Based on Experimental Flow Fields, J. of Mechanical Engineering Science, V14, 1972, 85-97.

[11] CEP, R., JANASEK A., PETRU J., CEPOVA L., CZAN A., VALICEK J.: Hard Machinable Machining of Cobalt-based Superalloy. Manufacturing Technology XIII/13, 2013, 226-231, UJEP : Usti n. Labem, ISSN 1213-2489.

[12] SAPIETOVA, A., SAGA, M., NOVAK, P.: Multi-software Platform for Solving of Multibody Systems Synthesis, Communications - Scientific Letters of the University of Zilina, vol. 14, No. 3, 43-48, 2012, ISSN 1335-4205.

[13] MOHYLA, P., TOMCIK, P., BENES, L., HLAVATY, I.: Effect of Post-welding Heat Treatment on Secondary Hardening of Welded Joints of Cr-Mo-v Steel. Metal Science and Heat Treatment 53 (7-8), 2011, 374-378, ISSN: 0026-0673.

[14] SAJGALIK, M., CZAN, A.: Studying of Processes in Cutting Zone by Non-destructive Methods, Technological Engineering, vol. 8, No. 2, University of Zilina, 2011.

[15] ZMINDAK, M., RIECKY, D.: Meshless Modelling of Laminate Mindlin Plates under Dynamic Loads Synthesis, Communications - Scientific Letters of the University of Zilina, vol. 14, No. 3, 2012, 24-31, ISSN 1335-4205.

[16] PANDA, A., DUPLAK, J., VOROBEL, T., JURKO, J., FABIAN, S.: Study of the Surface Material AISI 304 usable for Actuator after the Process of Turning, Applied Mechanics and Materials, vol. 460, 2014, 107-114, ISSN: 1660-9336.

[17] CZAN, A., TILLOVA, E., SEMCER, J., PILC, J.: Surface and Subsurface Residual Stresses after Machining and their Analysis by x-ray Diffraction. Communications - Scientific Letters of the University of Zilina, vol. 15, No. 2, 2013, 69-76. ISSN 1335-4205

[18] NAPRSTKOVA, N., HOLESOVSKY, F.: Admeasurement of Grinding Wheel Loss at FPTM. 24 $4^{\text {th }}$ Intern. Colloquium (Advanced manufacturing and repair technologies in vehicle industry), 159-164, 2007, ISBN 978-80-7194-962-6.

[19] VASILKO, K., PILC, J.: New Technological Knowledge of the Rotary Turning Tool, J. Manufacturing Technology, vol. 13, No. 4, 571-575, December 2013, ISSN: 1213-2489.

[20] MICHALIK, P., ZAJAC, J., HATALA, M.: Programming CNC Machines using Computer-aided Manufacturing Software, Advanced Science Letters, vol. 19, No. 2, 369-373, February 2013, ISSN: 19366612.

[21] NESLUSAN, M., CZAN, A., ZURPEL, U.: Analysis of the Heat Distribution when Grinding of a VT 9 Titanium Alloy and its Relation to Residual Tresses, Strojniski vestnik - J. of Mechanical Engineering, vol. 48, No. 10, 557-564, 2002, ISSN 0039-2480.

[22] MRKVICA, I., JANOS, M., SYSEL, P.: Contribution to Milling of Materials on Ni Base. Applied Mechanics and Materials, 217-219, 2012, 2056-2059. ISSN: 1660-9336 
[23] ZEBALA, W., SLODKI, B., STRUZIKIEWICZ, G.: Productivity and Reliability Improvement in Turning Inconel 718 Alloy - Case study, J. Eksploatacja i Niezawodnosc, vol. 15, No. 4, 421-426, 2013, ISSN: 1507-2711.

[24] WHITENTON, E.P., et al. in: High-speed Dual Spectrum Imaging for the Measurement of Metal Cutting Temperatures, Manufacturing Engineering Laboratory, NIST, Gaithersburg, 2010.

[25] PILC, J., MICIETOVA, A., SALAJ, J., CILliKOVA, M.: The Influence of the Selected Aspects in Planing Operations by using Auto-rotation Tool, Transactions of Famena, vol. 29, No. 2, 55-60, 2005, ISSN: 1333-1124.

[26] CEP, R., KOURIL, K., MRKVICA, I., JANASEK, I., PROCHAZKA, J.: Tests of Kyocera Tools when Discontinuos Cutting Conditions (in Czech). Strojirenska technologie, vol. XV, No. 3, 51-58, 2010, ISSN 1211-4162.

[27] LiTVAJ, I., PONISCIAKOVA, O., STANCEKOVA, D., DRBUL, M.: Knowledge Processes and their Implementation in Small Transport Companies, $1^{\text {th }}$ Intern. Conference Transport Means 2013, Kaunas, 153-156, October 2013, Code 102486, ISSN: $1822-$ $296 \mathrm{X}$

[28] HOLESOVSKY, F., NAPRSTKOVA, N., NOVAK, M.: GICS for Grinding Process Optimization. Manufacturing Technology, XII/12, 22-26, 2012, UJEP: Usti n. Labem, ISSN 1213-2489.

[29] CEP, R., JANASEK, A., CEPOVA, L., PETRU, J., HLAVATY, I., CAR, Z., HATALA, M.: Experimental Testing of Exchangeable Cutting Inserts Cutting Ability, Tehnicki Vjesnik 20 (1), 21-26, ISSN: 1330-3651.

[30] WHITENTON, E. P., IVESTER, R., et al. in: Simultaneous Visible and Thermal Imaging of Metals During Machining in Thermosense XXVII, Orlando, Intern. Society for Optical Engineering, 2005.

[31] VASILKO, K., PILC, J.: New Technological Knowledge of the Rotary Turning Tool, J. Manufacturing Technology, vol. 13, No. 4, 571-575, December 2013, ISSN: 1213-2489.

[32] KRAJCOVIC, M., BULEJ, V., SAPIETOVA, A., KURIC, I.: Intelligent Manufacturing Systems in Concept of Digital Factory, Communication - Scientific Letters of the University of Zilina, No. 2, 2012, ISSN 1335-4205.

[33] CUBOnOVA, N.: Post-processing of CL Data in CAD/CAM system Edgecam using the Constructor of Postprocessors. Manufacturing Technology: J. for Science, Research and Production, vol. 13, No. 2, 2013, 158-164. ISSN 1213-2489. 